\title{
A new concept for UAV landing gear shock vibration control using pre-straining spring momentum exchange impact damper
}

\author{
Lovely Son, Mulyadi Bur and Meifal Rusli
}

\begin{abstract}
This study proposes a new method for reducing the shock vibration response of an Unmanned Aerial Vehicle (UAV) during the landing process by means of the momentum exchange principle (MEID). The performance of the impact damper is improved by adding a pre-straining spring to the damper system. This research discusses the theoretical application of the damper to the UAV landing gear system. The UAV dynamics is first modeled as a simple lumped mass translational vibration system. Then we analyze a more complex two-dimensional model of UAV dynamics. This model consists of the main wheel, nose wheel and main body. Three cases of UAV landing gear mechanisms: without damper, with passive MEID (PMEID) and with pre-straining spring MEID (PSMEID) are simulated. The damper performance is evaluated from the maximum acceleration and force transmission to the main body. The energy balance calculation is conducted to investigate the performance of PSMEID. The simulation results show that the proposed PSMEID method is the most effective method for reducing the maximum acceleration and force transmission of UAV during impact landing.
\end{abstract}

\section{Keywords}

PSMEID, vibration, impact, shock, landing gear

\section{Introduction}

An Unmanned Aerial Vehicle (UAV) is an aircraft without any human crew. This vehicle is controlled remotely from a stationary or mobile command center. UAVs are controlled by radio frequency (directly from the ground or via satellites for wider ranges of operation) or autonomously (by on-board computers). Autonomous control of the UAV is based on pre-programmed flight plans using complex automation systems. All UAVs are equipped with the same features as normal aircrafts. The steering system, landing gear and shape of the vessel itself are similar to normal aircraft (Skorupka et al., 2010).

One important component in the UAV system is the landing gear. The basic function of the landing gear on a UAV is to maneuver it during its ground operations, which includes taxiing, takeoff and landing. The landing process is the most critical phase in the UAV ground operation because it involves a massive amount of impact energy transfer and the system has to be stable enough to operate under these conditions.
Dynamic loads on the UAV due to landing impact are recognized as the significant factor causing fatigue damage and dynamic stressing on the UAV structure. In addition, the shock-induced vibrations can lead to damage in the electrical components and contribute to the reduction of the autopilot capability to control the UAV position after landing maneuver. Several mechanisms have been proposed for dissipating the large amount of energy generation during touchdown landing impact.

The energy dissipation during the landing process can be achieved in different ways. One way is through

Department of Mechanical Engineering, Andalas University, Kampus Limau Manis, Padang, West Sumatera, Indonesia

Received: 23 October 2015; accepted: 2 July 2016

\section{Corresponding author:}

Lovely Son, Department of Mechanical Engineering, Andalas University, Kampus Limau Manis, Padang, West Sumatera, 25I63, Indonesia. Email: lovelyson@ft.unand.ac.id 
the use of Oleo-pneumatic shock absorbers, which are usually used by large commercial aircraft because they have a large capability to absorb the energy by pushing a volume of hydraulic fluid against volume of gas (Zdravko and Hinko, 2004). For lighter airplanes, the most common way for reducing the impact energy is by using beam springs or steel disc springs landing gear with flexible elements (Skorupka et al., 2010).

The UAV landing gear is constructed the same way as the landing gear for a commercial aircraft. For this type of aircraft, the impact loads' absorption during the landing process should be more effective because some precision sensors are installed on the UAV's electronic board. In small UAVs, the fixed spring landing gear is most often used (Khebbache, 2012 and Kumar, 2012). Some of the larger UAVs use the active landing gear system, which uses electric, pneumatic or hydraulic actuators. The larger sized UAVs have adequate thrust power and enough space to use a hydraulic system for a landing gear. However, for smaller sized UAVs, fitting hydraulics introduces a new problem related to the available space and mass. In addition, the active control for the landing gear needs enough electric power for the sensors, actuator and controller.

Recently, an electric control system using small control components for the landing gear has been developed. However, the main problem of using the electric control system is that they are sometimes not compatible with the mechanics. In landing gear control systems, mostly linear movements are needed. Of course there is a variety of electrical linear motors but they are expensive and not a light enough weight. This problem can be solved by using gear transmissions but this method also has its limitations by lowering power and torque. While the special linear actuator can be built, there are two main problems: price and availability. The price of a custom-made linear actuator can be much higher than the UAV itself.

A method has been developed by using the momentum exchange principle to reduce the acceleration peak of impact vibration problems. The Momentum Exchange Impact Damper (MEIDs) method was first used to solve the problem of floor impact vibration (Son et al., 2007). An application of MEID to the spacecraft landing process has been proposed (Iio et al., 2010). This technique can reduce the maximum acceleration of the craft at the time of landing.

The MEID reduces the shock vibration of an object by exchanging the momentum of the object with the damper. The MEID mechanism can be explained simply by using the three ball systems as shown in Figure 1. Before collision, the second ball had contact with the third ball. At the instant after the collision take place (as shown in Figure 1), the momentum and the kinetic energy of the first ball was transferred to the

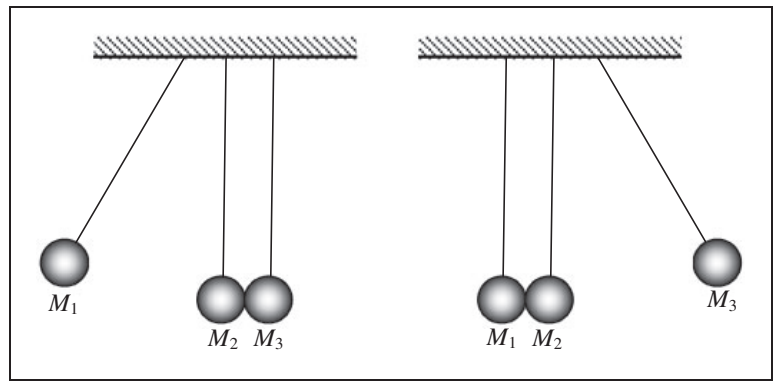

Figure I. Three balls system.

second and third balls. The momentum and energy exchanges continue while the masses remain in contact with each other. The momentum exchange mechanism, as explained using the three balls system, has been utilized for designing the passive momentum exchange impact damper (PMEID). In the PMEID application, the first ball which applies a shock load to the second ball represents the shock excitation force. The second ball acts as the main body that receives the shock load. The third ball represents the impact damper system that reduces the kinetic energy of the main body by means of momentum exchange mechanism.

The Active Momentum Exchange Impact Damper (AMEID) has been proposed to improve the damper performance by increasing the amount of momentum exchange between the main body and the damper (Son et al., 2008, 2010). The AMEID has been applied to the spacecraft landing system for reducing the maximum rebound of the spacecraft after landing (Hara et al., 2011). Even though the impact energy of the spacecraft decreases significantly by using AMEID, but it has some limitations such as its needs several sensors and a large actuator to resist large impact loads.

A simple method for increasing the MEID capability using the pre-straining spring mechanism (PSMEID) has been proposed (Son et al., 2015). This study proposes using PSMEID as the landing mechanism of the UAV. Thus, the main aim of this research is to verify the effectiveness of the PSMEID method in reducing the shock vibration response occurred during the UAV landing process.

\section{Dynamics of UAV landing gear}

The landing process of a UAV can be explained simply by using Figure 2 (Sanoopkumar, 2003). When a UAV descends on the runway, power is reduced further and the rate of descent and airspeed are slowed down. The aircraft is kept aligned with the center of the runway mainly by use of the rudder. The objective of the landing mechanism is to keep the aircraft safely flying just a few inches above the runway's surface until it loses flying speed (Nelson, 1998). In this condition, the 


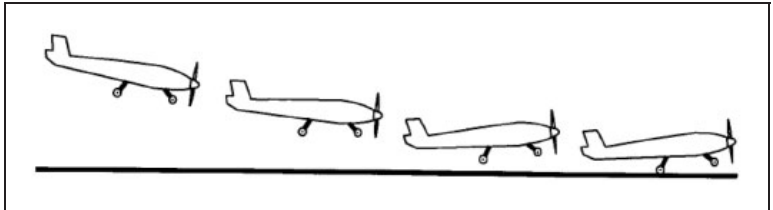

Figure 2. Aircraft landing process (Sanoopkumar, 2003).

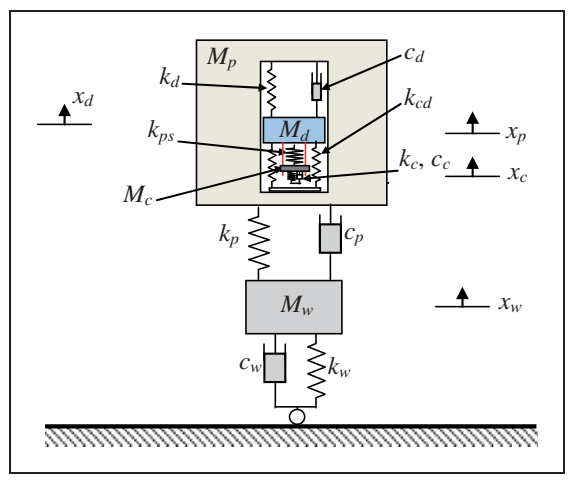

Figure 3. Simple model of UAV landing gear system with PSMEID.

aircraft's main wheels will strike the runway with a gentle bump. With the wheels of the main landing gear firmly on the runway, the pilot applies increasing back pressure on the control wheel. This holds the aircraft in a nose-high attitude which keeps the nose wheel from touching the runway until forward speed is much slower. The purpose of the landing gear mechanism is to avoid overstressing the UAV body and damaging the electrical components inside the UAV when the wheel touches down on the runway. To compare the effectiveness of the PSMEID method, the authors discuss two types of UAV landing models: the simple lumped mass translational model and the complex twodimensional rotational-translational model.

\section{I. Simple lumped mass translational model}

The simple lumped mass model of the UAV's landing gear system with PSMEID is shown in Figure 3. The UAV dynamics is described by a main mass $M_{p}$, which is supported by a landing gear system. The interaction between the main mass and the wheel system is modeled using a main spring $k_{p}$ and dashpot $c_{p}$. The wheel system consists of a wheel mass $M_{w}$, wheel spring $k_{w}$ and dashpot $c_{w}$. The PSMEID damper is positioned as described in Figure 3. The damper consists of a damper mass $M_{d}$ connected to the main mass using a damper spring $k_{d}$ and dashpot $c_{d}$. The damper mass $M_{d}$ interacts with the contact mass $M_{c}$ through a pre-straining spring $k_{p s}$. The contact mass contacts the main mass via a contact spring $k_{c}$ and contact damping $c_{c}$. The contact stiffness $k_{c d}$ is used as the passive contact spring of the MEID.

It is assumed that $x_{w}>x_{c}>x_{d}>x_{p}$. Then, by using Newton's Second Law of Motion, the equations of motion of the dynamical system in Figure 3 can be expressed by:

$$
\begin{gathered}
M_{p} \ddot{x}_{p}+M_{p} g-f_{p w}-f_{p d}+f_{c}=0 \\
M_{d} \ddot{x}_{d}+M_{d} g-f_{p s}+f_{t}+f_{p d}=0 \\
M_{c} \ddot{x}_{c}+M_{c} g+f_{p s}-f_{t}-f_{c}=0 \\
M_{w} \ddot{x}_{w}+M_{w} g+f_{p w}+f_{w}=0
\end{gathered}
$$

$f_{w}$ is the impulsive force generated when the wheel has contact with the ground. It is assumed that the UAV system drops with zero initial velocity. Therefore, the level of impulsive force is determined by the initial elevation drop of the UAV. During the contact period, the impulsive contact force is transmitted from the ground surface to the UAV wheel. The contact condition between the ground and the wheel is modelled by a contact spring and dashpot elements as shown in Figure 3. Therefore, the impulsive force can be calculated as follows:

$$
f_{w}= \begin{cases}k_{w} x_{w}+c_{w} \dot{x}_{w}, & \text { if } x_{w}<0 \\ 0, & \text { if } x_{w} \geq 0\end{cases}
$$

The contact condition between $M_{c}$ and $M_{p}$ is modeled using a contact spring $k_{c}$ and contact damping $c_{c}$. The contact force is derived from the stretch motion of the contact spring and the contact damping elements. This contact force is given by:

$f_{c}= \begin{cases}k_{c}\left(x_{p}-x_{c}-x_{0}\right)+c_{c}\left(\dot{x}_{p}-\dot{x}_{c}\right), & \text { if } x_{p}-x_{c}-x_{0} \geq 0 \\ 0, & \text { if } x_{p}-x_{c}-x_{0}<0\end{cases}$

The initial gap $x_{0}$ in equation (6) is introduced to obtain the optimum condition for transferring momentum from $M_{p}$ to $M_{d}$.

A pre-straining spring is added between $M_{c}$ and $M_{d}$ to increase the momentum exchange from the main mass to the damper mass. The pre-straining force value is controlled by adjusting the initial deflection of the pre-straining spring as shown in Figure 3. The pre-straining force $f_{p s}$ acting between $M_{c}$ and $M_{d}$ can be written as:

$$
f_{p s}=k_{p s}\left(x_{p s}+x_{c}-x_{d}\right)
$$


$f_{p w}$ is the interaction force through the spring $k_{p}$ and dashpot $c_{p}$. This force is calculated from the relative motion between mass $M_{p}$ and $M_{w}$ :

$$
f_{p w}=k_{p}\left(x_{w}-x_{p}\right)+c_{p}\left(\dot{x}_{w}-\dot{x}_{p}\right)
$$

The interaction force between $M_{p}$ and $M_{d}$ can be expressed by:

$$
f_{p d}=\left\{\begin{array}{cc}
k_{d}\left(x_{d}-x_{p}\right)+c_{d}\left(\dot{x}_{d}-\dot{x}_{p}\right), & \text { if }\left(x_{d}-x_{p}\right) \geq 0 \\
k_{d}\left(x_{d}-x_{p}\right)+c_{d}\left(\dot{x}_{d}-\dot{x}_{p}\right) & \\
+k_{c d}\left(x_{d}-x_{p}\right), & \text { if }\left(x_{d}-x_{p}\right)<0
\end{array}\right.
$$

It should be noted that the damping coefficient of MEID has a different value for forward and backward motion. The damping coefficient is zero for the forward motion and $c_{d}$ for the backward motion. This relationship is described mathematically by:

$$
c_{d}= \begin{cases}0, & \text { if }\left(\dot{x}_{d}-\dot{x}_{p}\right) \geq 0 \\ c_{d}, & \text { if }\left(\dot{x}_{d}-\dot{x}_{p}\right)<0\end{cases}
$$

A counteracting force $f_{t}$ is introduced between $M_{c}$ and $M_{d}$ to balance the pre-straining force. After the main mass collides with the contact spring, the counteracting force becomes zero. This relation can be expressed as:

$$
f_{t}= \begin{cases}k_{p s} x_{p s}, & \text { if }\left|f_{c}\right|=0 \text { and } f_{p w}<0 \\ 0, & \text { otherwise }\end{cases}
$$

\subsection{Two dimensional lumped mass translational-rotational model}

During the landing process, there are two stages for the landing mechanism:

1. The stage which starts when the main wheel initially touches the runway, which continues until the nose wheel touches the runway.

2. The stage which starts when the nose wheel touches the runway and continues until the aircraft comes to a standstill.

In the first stage, when the main wheel initially contacts the runway while the nose wheel is still airborne, the damping mechanism impact is activated by the damping component in the main wheel suspension system. In this research, a PSMEID-type absorber is utilized to reduce the shock load received by the UAV body due to a large impact force generated when the

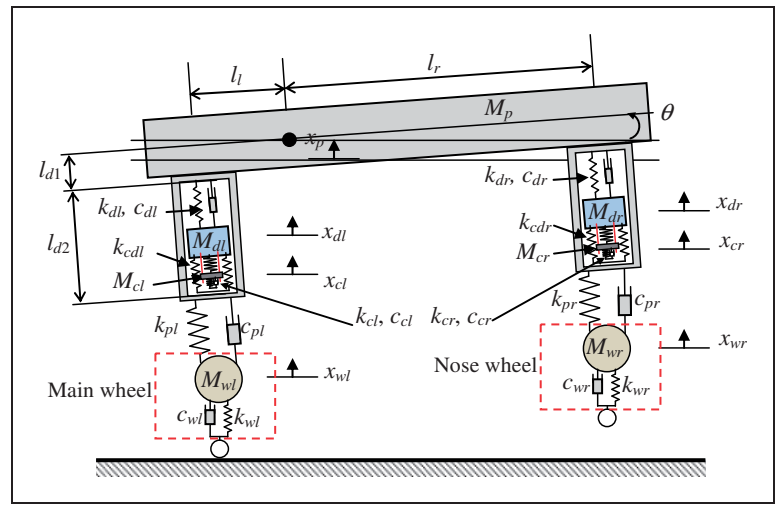

Figure 4. Dynamic model of the UAV landing gear system with PSMEID.

main wheel touches the runway. The evaluation is conducted by comparing the maximum acceleration response of the UAV at the instant after the main wheel contacts the ground.

A two-dimensional model of the UAV landing mechanism with PSMEID is shown in Figure 4. To derive the equations of motion of the system, forces working on the system are analyzed in detail. The forces are identified as follows:

1. The left and right wheel contact forces $f_{w l}$ and $f_{w r}$

When the wheels contact the ground, the contact forces are transmitted from the wheels spring and dashpot to the wheel's mass. These forces are given by:

$$
\begin{array}{r}
f_{w l}= \begin{cases}k_{w l} x_{w l}+c_{w l} \dot{x}_{w l}, & \text { if } x_{w l}<0 \\
0, & \text { if } x_{w l} \geq 0\end{cases} \\
f_{w r}= \begin{cases}k_{w r} x_{w r}+c_{w r} \dot{x}_{w r}, & \text { if } x_{w r}<0 \\
0, & \text { if } x_{w r} \geq 0\end{cases}
\end{array}
$$

2. The interaction forces between the main mass and the left and right wheel mass $f_{p w l}$ and $f_{p w r}$

The main mass $M_{p}$ connects with the wheel mass $M_{w l}$ and $M_{w r}$ via the spring and the dashpot. The interaction forces between them are given by:

$$
\begin{aligned}
& f_{p w l}=k_{p l}\left(x_{w l}-x_{p}+l_{l} \sin \theta\right)+c_{p l}\left(\dot{x}_{w l}-\dot{x}_{p}+l_{l} \frac{d}{d t}(\sin \theta)\right) \\
& f_{p w r}=k_{p r}\left(x_{w r}-x_{p}-l_{r} \sin \theta\right)+c_{p r}\left(\dot{x}_{w r}-\dot{x}_{p}-l_{r} \frac{d}{d t}(\sin \theta)\right)
\end{aligned}
$$


3. The interaction forces between the main mass and the left and right damper mass $f_{p d l}$ and $f_{p d r}$

The main mass interacts with the damper mass through the damper spring $\left(k_{d l}\right.$ and $\left.k_{d r}\right)$ and the contact spring $\left(k_{c d l}\right.$ and $\left.k_{c d r}\right)$. The interaction forces can be expressed as follows:

$$
\begin{gathered}
f_{p d l}= \begin{cases}f_{p d l 1}, & \text { if }\left(x_{d l}-x_{p}+l_{l} \sin \theta\right) \geq 0 \\
f_{p d l 1}+f_{p d l 2}, & \text { if }\left(x_{d l}-x_{p}+l_{l} \sin \theta\right)<0\end{cases} \\
f_{p d r}= \begin{cases}f_{p d r 1}, & \text { if }\left(x_{d r}-x_{p}-l_{r} \sin \theta\right) \geq 0 \\
f_{p d r 1}+f_{p d r 2}, & \text { if }\left(x_{d r}-x_{p}-l_{r} \sin \theta\right)<0\end{cases}
\end{gathered}
$$

where $f_{p d l 1}$ and $f_{p d r 1}$ are the interaction forces through the impact damper spring and dashpot as given by:

$$
\begin{gathered}
f_{p d l 1}=k_{d l}\left(x_{d l}-x_{p}+l_{l} \sin \theta\right)+c_{d l}\left(\dot{x}_{d l}-\dot{x}_{p}+l_{l} \frac{d}{d t}(\sin \theta)\right) \\
f_{p d r 1}=k_{d r}\left(x_{d r}-x_{p}-l_{r} \sin \theta\right)+c_{d r}\left(\dot{x}_{d r}-\dot{x}_{p}-l_{r} \frac{d}{d t}(\sin \theta)\right)
\end{gathered}
$$

The interaction forces through the contact spring are calculated as follows:

$$
\begin{aligned}
& f_{p d l 2}=k_{c d l}\left(x_{d l}-x_{p}+l_{l} \sin \theta\right) \\
& f_{p d r 2}=k_{c d r}\left(x_{d r}-x_{p}-l_{r} \sin \theta\right)
\end{aligned}
$$

\section{The pre-straining forces $f_{p s l}$ and $f_{p s r}$}

The pre-straining springs are introduced between the damper mass and the contact mass. The pre-straining forces acting on the main and nose landing gears are given by:

$$
\begin{aligned}
& f_{p s l}=k_{p s l}\left(x_{p s l}+x_{c l}-x_{d l}\right) \\
& f_{p s r}=k_{p s r}\left(x_{p s r}+x_{c r}-x_{d r}\right)
\end{aligned}
$$

5. The interaction forces between the main mass and the left and right contact mass $f_{p c l}$ and $f_{p c r}$

The contact forces between the main mass and the contact masses can be written as:

$$
\begin{gathered}
f_{p c l}= \begin{cases}k_{c l}\left(x_{p}-l_{l} \sin \theta-x_{c l}-x_{0 l}\right)+c_{c l}\left(\dot{x}_{p}-l_{l} \frac{d}{d t} \sin \theta-\dot{x}_{c l}\right), & \text { if } x_{p}-l_{l} \sin \theta-x_{c l}-x_{0 l} \geq 0 \\
0, & \text { if } x_{p}-l_{l} \sin \theta-x_{c l}-x_{0 l}<0\end{cases} \\
f_{p c r}= \begin{cases}k_{c r}\left(x_{p}+l_{r} \sin \theta-x_{c r}-x_{0 r}\right)+c_{c r}\left(\dot{x}_{p}+l_{r} \frac{d}{d t} \sin \theta-\dot{x}_{c r}\right), & \text { if } x_{p}+l_{r} \sin \theta-x_{c r}-x_{0 r} \geq 0 \\
0, & \text { if } x_{p}+l_{r} \sin \theta-x_{c r}-x_{0 r}<0\end{cases}
\end{gathered}
$$

The damping coefficients $c_{d l}$ and $c_{d r}$ in equations (17) and (18) only work in a backwards motion. In the case of forward motion, it has zero values. This relationship, can be explained mathematically by:

$$
c_{d l}=\left\{\begin{array}{cl}
0, & \left(\dot{x}_{d}-\dot{x}_{p}+\frac{d}{d t}\left(l_{l} \sin \theta\right)\right) \geq 0 \\
c_{d l}, & \left(\dot{x}_{d}-\dot{x}_{p}+\frac{d}{d t}\left(l_{l} \sin \theta\right)\right)<0
\end{array}\right.
$$

and

$$
c_{d r}=\left\{\begin{array}{cl}
0, & \left(\dot{x}_{d}-\dot{x}_{p}-\frac{d}{d t}\left(l_{r} \sin \theta\right)\right) \geq 0 \\
c_{d r}, & \left(\dot{x}_{d}-\dot{x}_{p}-\frac{d}{d t}\left(l_{r} \sin \theta\right)\right)<0
\end{array}\right.
$$

6. The counteracting forces $f_{t l}$ and $f_{t r}$

The counteracting forces $f_{t l}$ and $f_{t r}$ are applied between the damper mass and the contact mass to counteract forces from the pre-straining spring. The counteracting forces work before the main mass collides with the contact mass. After collision, the counteracting force becomes zero. This relation can be expressed as:

$$
\begin{aligned}
& f_{t l}= \begin{cases}k_{p s l} x_{p s l}, & \text { if }\left|f_{p c l}\right|=0 \text { and } f_{p w l}<0 \\
0, & \text { otherwise }\end{cases} \\
& f_{t r}= \begin{cases}k_{p s r} x_{p s r}, & \text { if }\left|f_{p c r}\right|=0 \text { and } f_{p w r}<0 \\
0, & \text { otherwise }\end{cases}
\end{aligned}
$$


The equations of motion for the UAV landing system are derived from the Newton's Second Law using the balance of moments and forces acting on the UAV system. For the UAV's main mass, the equations are given by:

$$
\begin{aligned}
& I_{G} \ddot{\theta}+P_{m}+\left(f_{p w l}+f_{p d l}\right) l_{l} \cos \theta-\left(f_{p w r}+f_{p d r}\right) l_{r} \cos \theta \\
& \quad-f_{p c l} l_{l} \cos \theta+f_{p c r} l_{r} \cos \theta-f_{p d l 1} l_{d 1} \sin \theta \\
& \quad-\left(f_{p w l}+f_{p d l 2}\right) l_{d 2} \sin \theta-f_{p d r 1} l_{d 1} \sin \theta \\
& \quad-\left(f_{p w r}+f_{p d r 2}\right) l_{d 2} \sin \theta+f_{p c l} l_{d 2} \sin \theta+f_{p c r} l_{d 2} \sin \theta=0
\end{aligned}
$$

$$
M_{p} \ddot{x}_{p}+M_{p} g-f_{p w l}-f_{p d l}-f_{p w r}-f_{p d r}+f_{p c l}+f_{p c r}=0
$$

By applying the forces balance to the left and right PSMEID mass, then the equations of motion of the damper masses can be expressed by:

$$
\begin{aligned}
& M_{d l} \ddot{x}_{d l}+M_{d l} g+f_{p d l}+f_{t l}-f_{p s l}=0 \\
& M_{d r} \ddot{x}_{d r}+M_{d r} g+f_{p d r}+f_{t r}-f_{p s r}=0
\end{aligned}
$$

The equations of motion of the other components are calculated according to the same procedure as was used in equation (31) and (32). The balance of forces acting on the left and right wheel mass can be expressed as follows:

$$
\begin{gathered}
M_{w l} \ddot{x}_{w l}+M_{w l} g+f_{p w l}+f_{w l}=0 \\
M_{w r} \ddot{x}_{w r}+M_{w r} g+f_{p w r}+f_{w r}=0
\end{gathered}
$$

The equations of motion for the left and right contact masses are given by:

$$
\begin{gathered}
M_{c l} \ddot{x}_{c l}+M_{c l} g+f_{p s l}-f_{t l}-f_{p c l}=0 \\
M_{c r} \ddot{x}_{c r}+M_{c r} g+f_{p s r}-f_{t r}-f_{p c r}=0
\end{gathered}
$$

The $l$ and $r$ indexes in equations (29)-(36) denote the main and nose landing gear. Variable $P_{m}$ in equation (29) is the additional nose pitching moment due to a lift force at the tail wing. At the instant after the nose gear touches the ground, the value of $P_{m}$ becomes zero. In the simulation, the nominal value of $P_{m}$ is selected to be 0 N.m.

\section{Simulation study and discussion}

The nominal values of the simulation parameters are given in Table 1. For the simple lumped mass model, the initial conditions are given such that the UAV drops with zero initial velocity from the initial elevation $h=0.05 \mathrm{~m}$. For the two-dimensional model, the UAV mass distributioan is selected such that the main gear is caryying about $80 \%$ of the total payload and the nose gear is supporting $20 \%$ of the total load (Sadrey, 2009). The initial pitching angle for the two-dimensional model is selected $15^{\circ}$.

\section{I. Simple lumped mass translational model}

To evaluate the PSMEID performance applied to the simple lumped mass translational model of the UAV's landing gear system, a comparison study was conducted. For this purpose, two cases of landing gear with passive type MEID (PMEID) and without MEID as shown in Figure 5 were evaluated. The nominal UAV parameters (as depicted in Table 1) were used in the simulations.

Figure 6 shows the UAV main mass acceleration and wheel displacement for the case without the damper. The UAV initially drops with zero initial velocity. During the dropping period, the main mass acceleration is the same as the gravitational acceleration. The negative value of the acceleration indicates that the motion is downward. At the instant after the wheel touches the ground, the main mass acceleration increases and reaches its maximum value at $t=0.15$ second. During $t=0.24-0.33$ second, the main mass is rebounded and its acceleration is equal to the gravitational acceleration as shown in Figure 6. In this period, the contact force between the wheel and the ground is zero. The wheel has contact with the ground for the second time at $t=0.33$ second. After this time, the main mass motion becomes the damped vibration response. It can be observed from Figure 6 that the main mass displacement is stable after 1 second. Figure 6 shows that the value of the static displacement of the main mass is close to $0.01 \mathrm{~m}$.

The contact force response between the wheel and the ground is depicted in Figure 7. It can be shown from Figure 7 that the contact force is zero during the rebound period ( $0.24-0.33$ second).

The damper mass $\left(M_{d}\right)$ used for PMEID is $0.5 \mathrm{~kg}$. This value is equal to $4 \%$ of the UAV's total mass. In the comparison study, the optimal contact condition for PMEID was selected to achieve acceptable simulation results. Some simulations using several contact stiffness $\left(k_{c d}\right)$ were conducted to obtain the optimum value of the contact stiffness. Figure 8 shows the maximum acceleration of the UAV's main mass versus the PMEID's contact stiffness. As shown in Figure 8, the maximum acceleration is not greatly affected by the variation of the PMEID's contact stiffness. The minimum values of the main mass acceleration peak 
Table I. Nominal simulation parameters.

\begin{tabular}{|c|c|c|c|}
\hline No & Parameters & Value & Unit \\
\hline I & Main mass of $U A V, M_{p}$ & 11.8 & $\mathrm{~kg}$ \\
\hline 2 & Rotational inertia of UAV, $I_{G}$ & 1.966 & $\mathrm{~kg} \cdot \mathrm{m}^{2}$ \\
\hline 3 & Wheel mass of the main landing gear, $M_{w l}$ & 0.021 & kg \\
\hline 4 & Wheel mass of the nose landing gear, $M_{w r}$ & 0.031 & $\mathrm{~kg}$ \\
\hline 5 & Wheel mass, $M_{w}$ & 0.021 & $\mathrm{~kg}$ \\
\hline 6 & Damper mass of the main landing gear, $M_{d l}$ & 0.5 & $\mathrm{~kg}$ \\
\hline 7 & Damper mass of the nose landing gear, $M_{d r}$ & 0.125 & $\mathrm{~kg}$ \\
\hline 8 & Damper mass, $M_{d}$ & 0.5 & $\mathrm{~kg}$ \\
\hline 9 & Contact mass of the main landing gear, $M_{c l}$ & 0.001 & $\mathrm{~kg}$ \\
\hline 10 & Contact mass of the nose landing gear, $M_{c r}$ & 0.001 & $\mathrm{~kg}$ \\
\hline II & Contact mass, $M_{c}$ & 0.001 & $\mathrm{~kg}$ \\
\hline II & $I_{d l}($ see Figure 4$)$ & 0.083 & $\mathrm{~m}$ \\
\hline 12 & $I_{d 2}($ see Figure 4$)$ & 0.165 & $\mathrm{~m}$ \\
\hline 13 & Horisontal distance from CG to main landing gear, $I_{l}$ & 0.061 & $\mathrm{~m}$ \\
\hline 14 & Horisontal distance from CG to nose landing gear, $I_{r}$ & 0.244 & $\mathrm{~m}$ \\
\hline 15 & Left wheel contact stiffness, $k_{w l}$ & $1 \times 10^{4}$ & $\mathrm{~N} / \mathrm{m}$ \\
\hline 16 & Right wheel contact stiffness, $k_{w r}$ & $1 \times 10^{4}$ & $\mathrm{~N} / \mathrm{m}$ \\
\hline 17 & Wheel contact stiffness, $k_{w}$ & $1 \times 10^{4}$ & $\mathrm{~N} / \mathrm{m}$ \\
\hline 18 & Suspension stiffness of main landing gear, $k_{p l}$ & $2 \times 10^{5}$ & $\mathrm{~N} / \mathrm{m}$ \\
\hline 19 & Suspension stiffness of nose landing gear, $k_{p r}$ & $2 \times 10^{5}$ & $\mathrm{~N} / \mathrm{m}$ \\
\hline 20 & Landing gear suspension stiffness, $k_{p}$ & $2 \times 10^{5}$ & $\mathrm{~N} / \mathrm{m}$ \\
\hline 21 & PMEID contact stiffness of main landing gear, $k_{c d l}$ & $1 \times 10^{4}$ & $\mathrm{~N} / \mathrm{m}$ \\
\hline 22 & PMEID contact stiffness of nose landing gear, $k_{c d r}$ & $1 \times 10^{4}$ & $\mathrm{~N} / \mathrm{m}$ \\
\hline 23 & PMEID contact stiffness, $k_{c d}$ & $1 \times 10^{4}$ & $\mathrm{~N} / \mathrm{m}$ \\
\hline 24 & Main landing gear impact damper stiffness, $k_{d l}$ & 0 & $\mathrm{~N} / \mathrm{m}$ \\
\hline 25 & Nose landing gear impact damper stiffness, $k_{d r}$ & 0 & $\mathrm{~N} / \mathrm{m}$ \\
\hline 26 & Landing gear impact damper stiffness, $k_{d}$ & 0 & $\mathrm{~N} / \mathrm{m}$ \\
\hline 24 & PSMEID contact stiffness of main landing gear, $k_{c l}$ & $1 \times 10^{5}$ & $\mathrm{~N} / \mathrm{m}$ \\
\hline 25 & PSMEID contact stiffness of nose landing gear, $k_{c r}$ & $1 \times 10^{5}$ & $\mathrm{~N} / \mathrm{m}$ \\
\hline 26 & Main landing gear suspension damping factor, $c_{p l}$ & $1 \times 10^{2}$ & N.s/m \\
\hline 27 & Nose landing gear suspension damping factor, $c_{p r}$ & $1 \times 10^{2}$ & N.s/m \\
\hline 28 & Landing gear suspension damping factor, $c_{p}$ & $1 \times 10^{2}$ & N.s/m \\
\hline 29 & Main landing gear impact damper damping coefficient, $c_{d l}$ & $1 \times 10^{3}$ & N.s/m \\
\hline 30 & Nose landing gear impact damper damping coefficient, $c_{d r}$ & $1 \times 10^{3}$ & N.s/m \\
\hline 31 & Landing gear impact damper damping coefficient, $c_{d}$ & $1 \times 10^{3}$ & N.s/m \\
\hline 32 & PSMEID contact damping of main landing gear, $c_{c l}$ & 20 & N.s/m \\
\hline 33 & PSMEID contact damping of nose landing gear, $c_{c r}$ & 20 & N.s/m \\
\hline 34 & PSMEID contact damping, $c_{c}$ & 20 & N.s/m \\
\hline 35 & PMEID contact damping, $c_{c d}$ & 0 & N.s/m \\
\hline 36 & Main landing gear pre-straining displacement, $x_{p s l}$ & 0.24 & $\mathrm{~m}$ \\
\hline 37 & Nose landing gear pre-straining displacement, $x_{p s r}$ & 0.08 & $\mathrm{~m}$ \\
\hline 38 & Landing gear pre-straining displacement, $x_{p s}$ & 0.24 & $\mathrm{~m}$ \\
\hline 39 & Initial gap of main landing gear, $x_{0 /}$ & $4.4 \times 10^{-4}$ & $\mathrm{~m}$ \\
\hline 40 & Initial gap of nose landing gear, $x_{0 r}$ & $4.4 \times 10^{-4}$ & $\mathrm{~m}$ \\
\hline 41 & Initial gap, $x_{0}$ & $4.8 \times 10^{-4}$ & $\mathrm{~m}$ \\
\hline 42 & Initial drop elevation, $h$ & 0.05 & $\mathrm{~m}$ \\
\hline
\end{tabular}




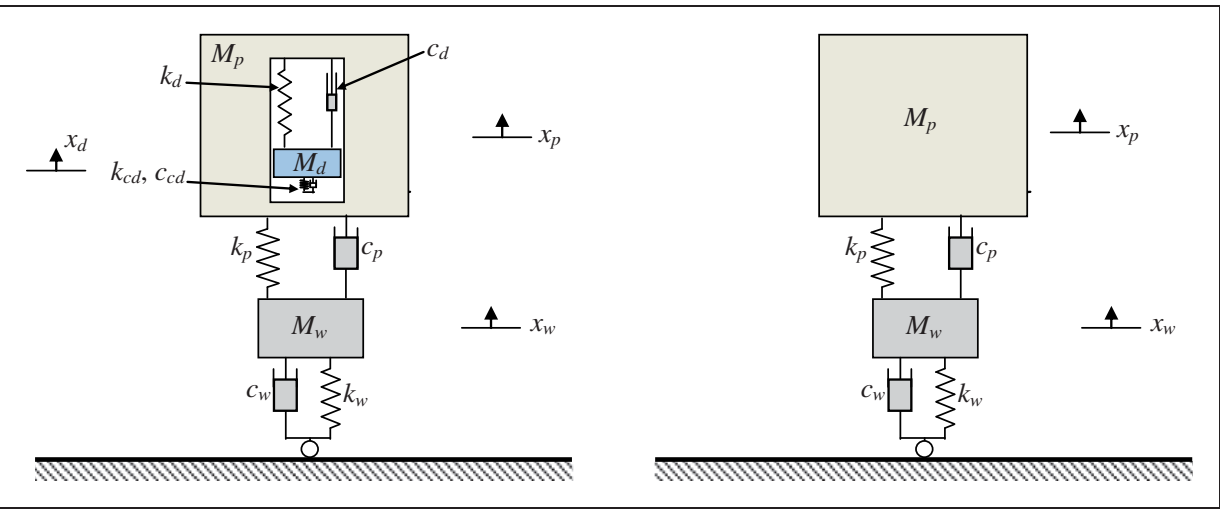

Figure 5. Simple model of UAV landing mechanism with and without PMEID.

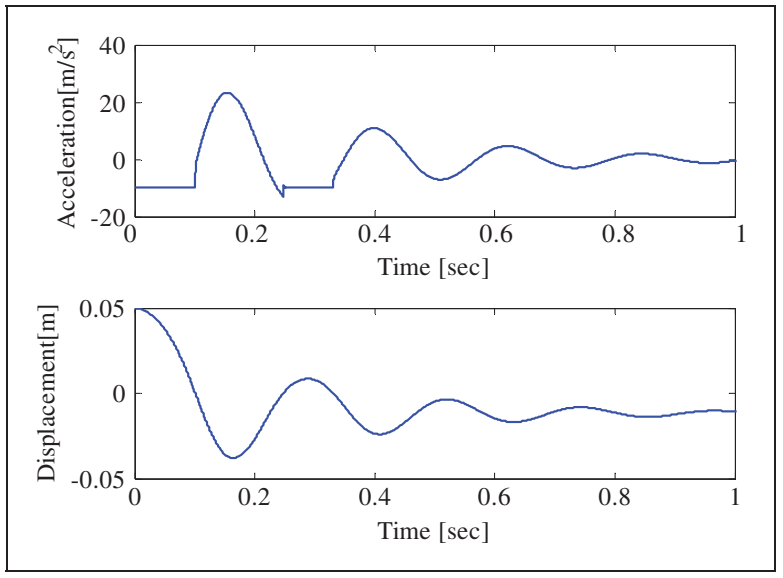

Figure 6. Main mass acceleration and wheel displacement.

can be obtained using $k_{c d}<1.5 \times 10^{4} \mathrm{~N} / \mathrm{m}$ as shown in Figure 8. Alternatively, the optimal contact stiffness can also be calculated by: (Son et al., 2010).

$$
k_{c d(o p t)}=M_{d} \omega_{f}^{2}\left(\frac{9\left(9-\beta^{2}\right)}{9(\mu+1)-\beta^{2}}\right)
$$

where

$$
\beta=\frac{\omega_{n}}{\omega_{f}}, \quad \mu=\frac{M_{d}}{M_{p}} \text { and } \omega_{f} \approx \sqrt{\frac{k_{w}}{M_{p}+M_{d}+M_{w}}}
$$

In the case of a large frequency ratio $\left(\omega_{n} / \omega_{f}>>\right)$ as used in this simulation model, the optimum contact stiffness can be expressed by:

$$
k_{c d(o p t)}=9 M_{d} \omega_{f}^{2}
$$

where $\omega_{n}$ and $\omega_{f}$ are the system's natural frequency and the excitation frequency, respectively. Calculation of

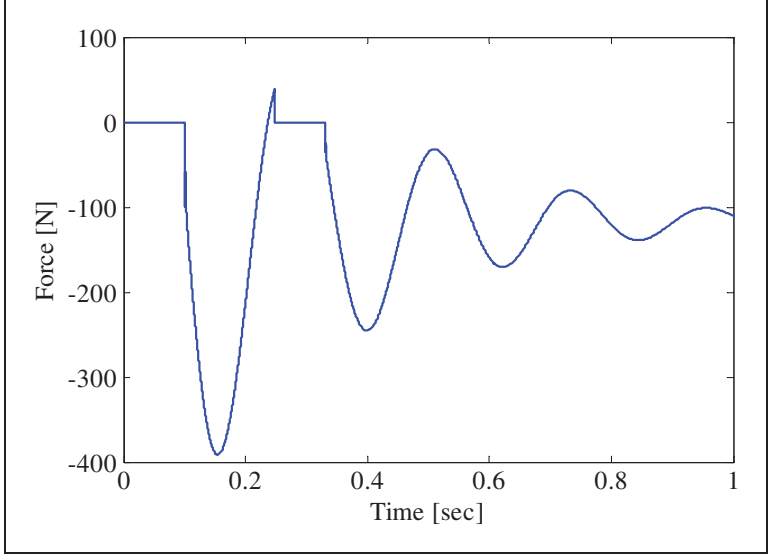

Figure 7. Wheel contact force.

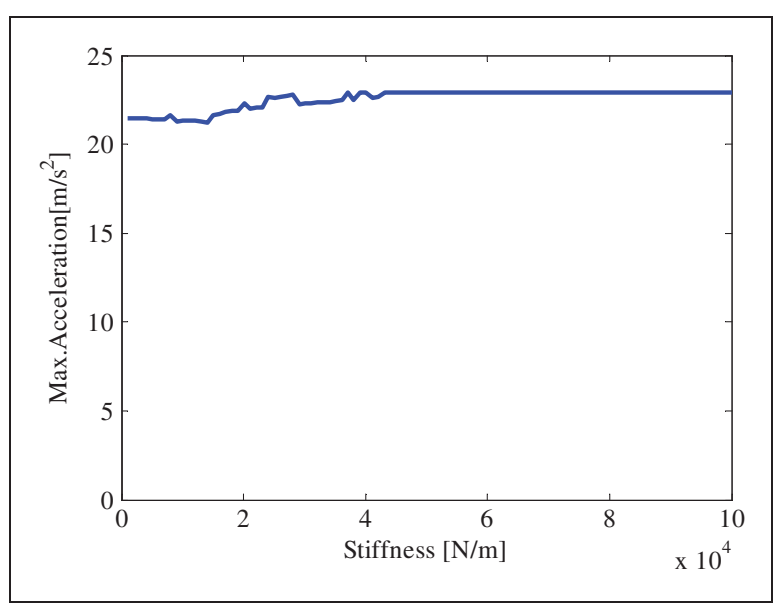

Figure 8. $k_{c d}$ vs maximum acceleration.

the contact stiffness in equation (39) using the simulation parameters in Table 1 resulting in the optimal contact stiffness $k_{c d}=3.65 \times 10^{3} \mathrm{~N} / \mathrm{m}$. This result agrees with the optimal condition of the contact stiffness 


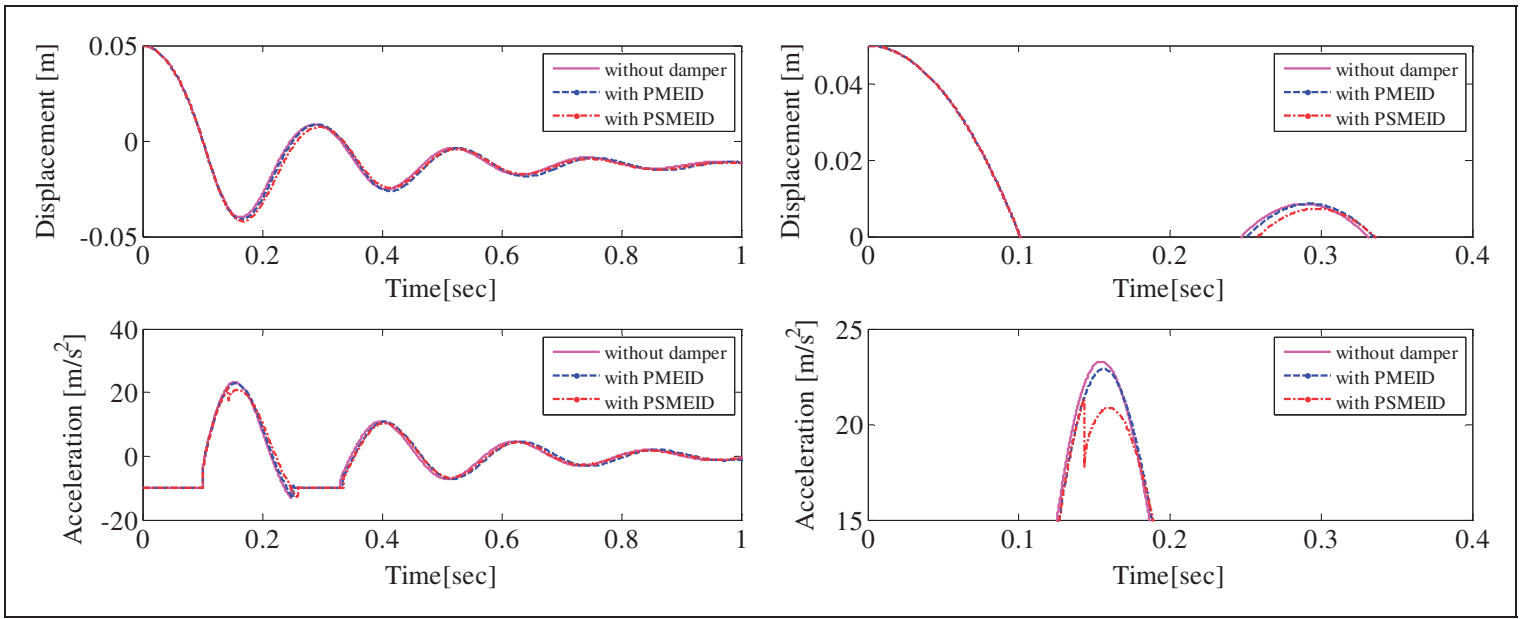

Figure 9. Displacement and acceleration of UAV and its enlargement.

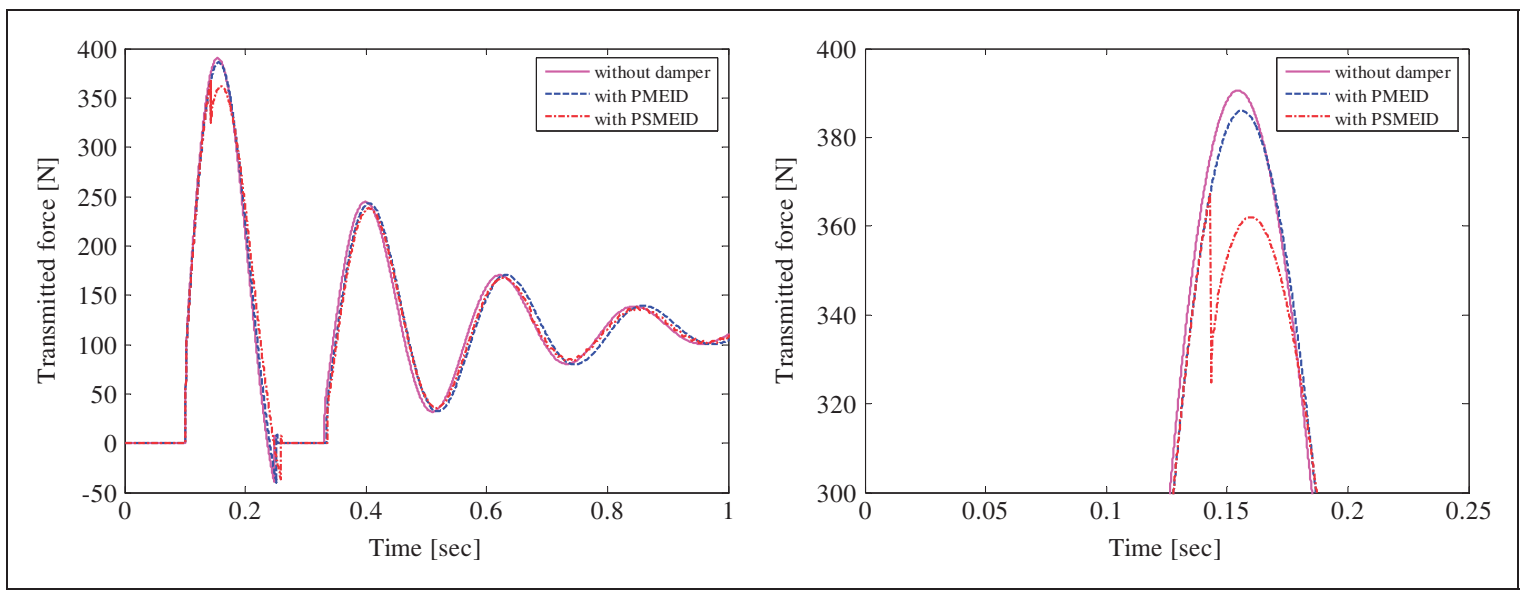

Figure 10. Transmitted force to the main body and its enlargement.

$k_{c d}<1.5 \times 10^{4} \mathrm{~N} / \mathrm{m}$ as shown in Figure 8. Meanwhile, the optimum amount of momentum transferred using the PMEID can be achieved using the small value of contact damping. Based on these results, the contact stiffness and the contact damping values that were used in the simulations for next section are: $k_{c d}=1 \times$ $10^{4} \mathrm{~N} / \mathrm{m}$ and $c_{c d}=0$.

Figure 9 shows the simulation results of the UAV's main mass displacement and acceleration for three cases: without damper, with PMEID and with PSMEID. The simulation uses the nominal parameters shown in Table 1. The PSMEID mass is the same weight as that used in the PMEID. The right side of Figure 9 is an enlargement of the graph from 0 to 0.4 second.

A comparison of the transmitted force response acting on the main mass obtained using the three cases is shown in Figure 10. As seen in Figure 10, the maximum value of transmitted force is reduced by using PMEID and PSMEID. The percentage of the transmitted force response reduction obtained using PMEID and PSMEID are $1 \%$ and $6 \%$, respectively.

\subsection{Energy balance analysis}

In order to increase confidence in the analysis result, the energy balance computations was conducted. The energy balance was analyzed through the use of the following five definitions of non-dimensional energy categories (Hurmuzlu, 1998).

1. The percentile energy of the main system, $E_{m}$ :

$$
E_{m}=\frac{K E_{M p}+K E_{M w}+P E_{k p}+P E_{k w}}{P E_{g}^{0}}
$$

where $K E_{M p}, K E_{M w}$ are kinetic energy of the main mass and wheel mass while $P E_{k p}$ and $P E_{k w}$ are 
elastic energy stored in the main spring $k_{p}$ and the wheel spring $k_{w}$. The initial gravitational energy of the system $P E_{g}^{0}$ is calculated by:

$$
P E_{g}^{0}=\left(M_{p}+M_{d}+M_{c}+M_{w}\right) g h
$$

The kinetic and potential energies in equation (40) are calculated as follows:

$$
\begin{gathered}
K E_{M p}=\frac{1}{2} M_{p} \dot{x}_{p}^{2} \\
K E_{M w}=\frac{1}{2} M_{w} \dot{x}_{w}^{2} \\
P E_{k p}=\frac{1}{2} k_{p}\left(x_{w}-x_{p}\right)^{2} \\
P E_{k w}=-\frac{1}{4} k_{w}\left(x_{w}\left|x_{w}\right|-x_{w}^{2}\right)
\end{gathered}
$$

2. The percentile energy of the impact damper, $E_{d}$ :

$$
E_{d}=\frac{K E_{M d}+K E_{M c}+P E_{k d}+P E_{k p s}}{P E_{g}^{0}}
$$

$K E_{M d}$ and $K E_{M c}$ in equation (46) are kinetic energy of $M_{d}$ and $M_{c}$ while $P E_{k d}$ and $P E_{k p s}$ are elastic energy of spring $k_{d}$ and $k_{p s}$. The kinetic and potential energy components in equation (46) are defined as:

$$
\begin{gathered}
K E_{M d}=\frac{1}{2} M_{d} \dot{x}_{d}^{2} \\
K E_{M c}=\frac{1}{2} M_{c} \dot{x}_{c}^{2} \\
P E_{k d}=\frac{1}{2} k_{d}\left(x_{d}-x_{p}\right)^{2} \\
P E_{k p s}=\frac{1}{2} k_{p s}\left(x_{c}-x_{d}+x_{p s}\right)^{2}
\end{gathered}
$$

3. The percentile energy of the contact spring, $E_{c}$ :

$$
E_{c}=\frac{P E_{k c d}+P E_{k c}}{P E_{g}^{0}}
$$

The potential energy of the contact spring $P E_{k c d}$ and $P E_{k c}$ are calculated by:

$$
P E_{k c d}=-\frac{1}{4} k_{c d}\left(\left(x_{d}-x_{p}\right)\left|x_{d}-x_{p}\right|-\left(x_{d}-x_{p}\right)^{2}\right)
$$

$$
P E_{k c}=\frac{1}{4} k_{c}\left(\left(x_{p}-x_{c}-x_{0}\right)\left|x_{p}-x_{c}-x_{0}\right|+\left(x_{p}-x_{c}-x_{0}\right)^{2}\right)
$$

4. The percentile of gravitation energy, $E_{g}$ :

$$
E_{g}=\frac{P E_{g}}{P E_{g}^{0}}
$$

where

$$
P E_{g}=M_{p} g x_{p}+M_{d} g x_{d}+M_{c} g x_{c}+M_{w} g x_{w}
$$

5. The percentile of dissipation energy, $E_{d s}$ :

$E_{d s}=\frac{P E_{g}^{0}+P E_{k p s}^{0}-\left\{\begin{array}{l}\left(K E_{M p}+K E_{M w}+P E_{k p}+P E_{k w}\right. \\ +K E_{M d}+K E_{M c}+P E_{k d}+P E_{k p s} \\ \left.+P E_{k c d}+P E_{k c}+P E_{g}\right)\end{array}\right\}}{P E_{g}^{0}+P E_{k p s}^{0}}$

or

$E_{d s}=1-\frac{\left\{\begin{array}{l}\left(K E_{M p}+K E_{M w}+P E_{k p}+P E_{k w}+K E_{M d}\right. \\ \left.+K E_{M c}+P E_{k d}+P E_{k p s}+P E_{k c d}+P E_{k c}+P E_{g}\right)\end{array}\right\}}{P E_{g}^{0}+P E_{k p s}^{0}}$

where

$$
P E_{k p s}^{0}=\frac{1}{2} k_{p s} x_{p s}^{2}
$$

The exchanges between energy components of the UAV with PSMEID are shown in Figure 11. The UAV initially drops from the starting elevation $h$. The initial energy of the system consists of the

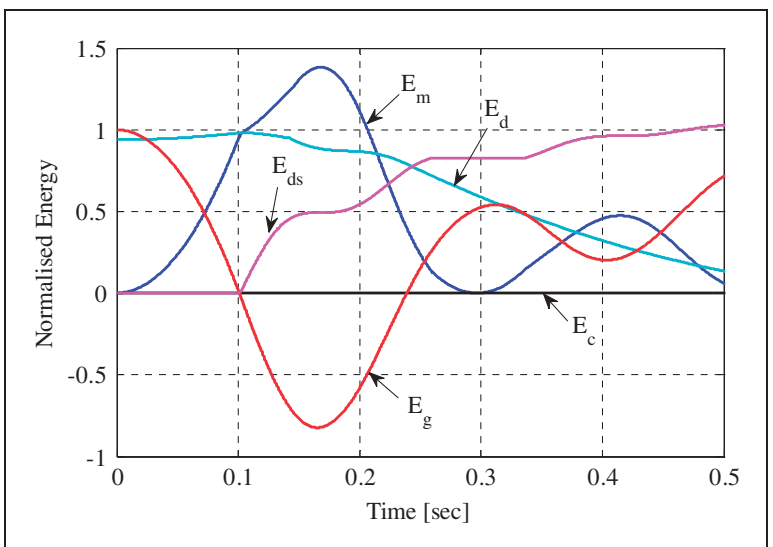

Figure II. Energy transfer using PSMEID. 
gravitational energy $P E_{g}^{0}$ and the elastic energy stored by the pre-straining spring $P E_{k p s}^{0}$. We can observe from Figure 11 that the total non-dimensional energy $E_{m}+E_{d}+E_{c}+E_{g}+E_{d s}$ is constant. From $t=0$ until 0.1 second, the UAV is in free flight and the exchange from the gravitational energy to the UAV kinetic energy occurs. At $t=0.1$, the wheel comes into contact with the ground surface as shown in Figure 11. During the initial contact with the surface, part of the energy is converted into dissipation energy $E_{d s}$ and part of the energy is transferred to the damper mass using the momentum exchange mechanism. It can be shown from Figure 11 that the percentage of energy transferred to the damper during the contact duration is twice that of was dispersed into heat loss. This result indicates that the impact damper is effective for reducing the shock vibration energy of the main mass. The negative value of the gravitational energy during the contact duration $(0.1<t<0.23)$ due to the position of the mass is located below the reference level.

\subsection{Two-dimensional lumped mass translational-rotational model}

To compare the effectiveness of the PSMEID method, the simulation results of the two-dimensional lumped mass model with and without PMEID were analyzed (depicted in Figure 12). It should be noted that the case without damper refers to the landing gear system with passive spring and dashpot elements. The weight of the damper masses used in the PMEID are the same as those used in the PSMEID mechanism.

Figure 13 shows the time histories of the UAV displacement and acceleration that were obtained from the simulation using the nominal parameters given in Table 1 . The aircraft falls with zero initial velocity from

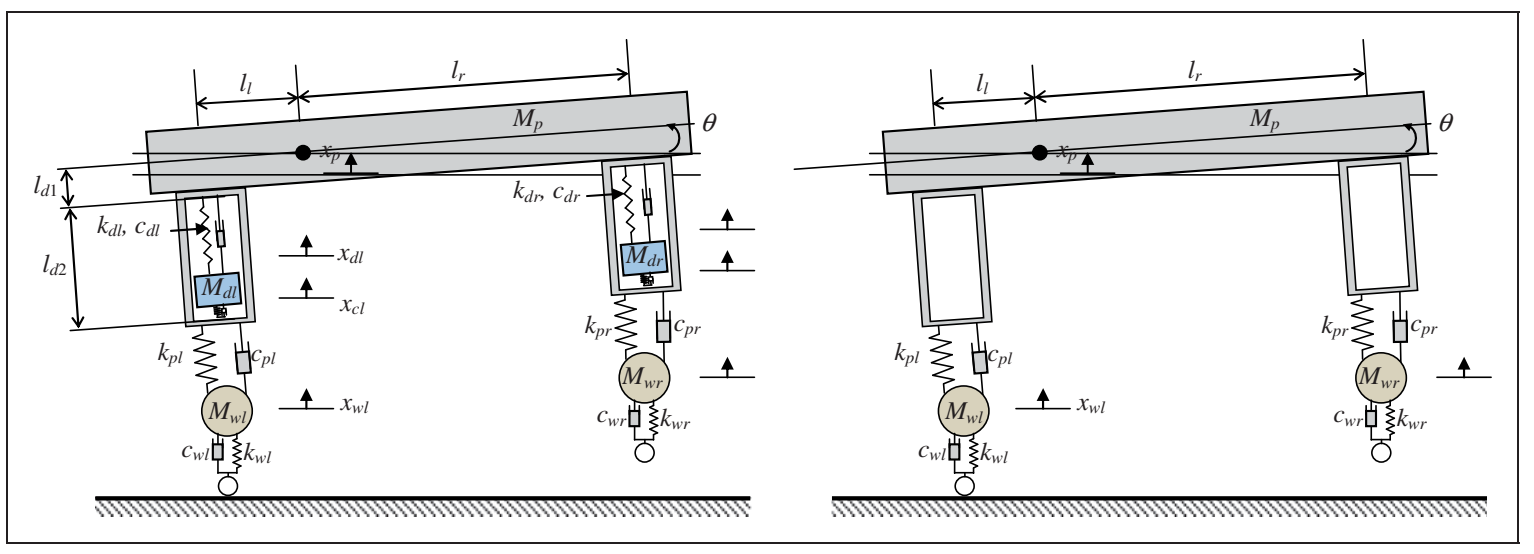

Figure I2. UAV dynamic model with and without PMEID.

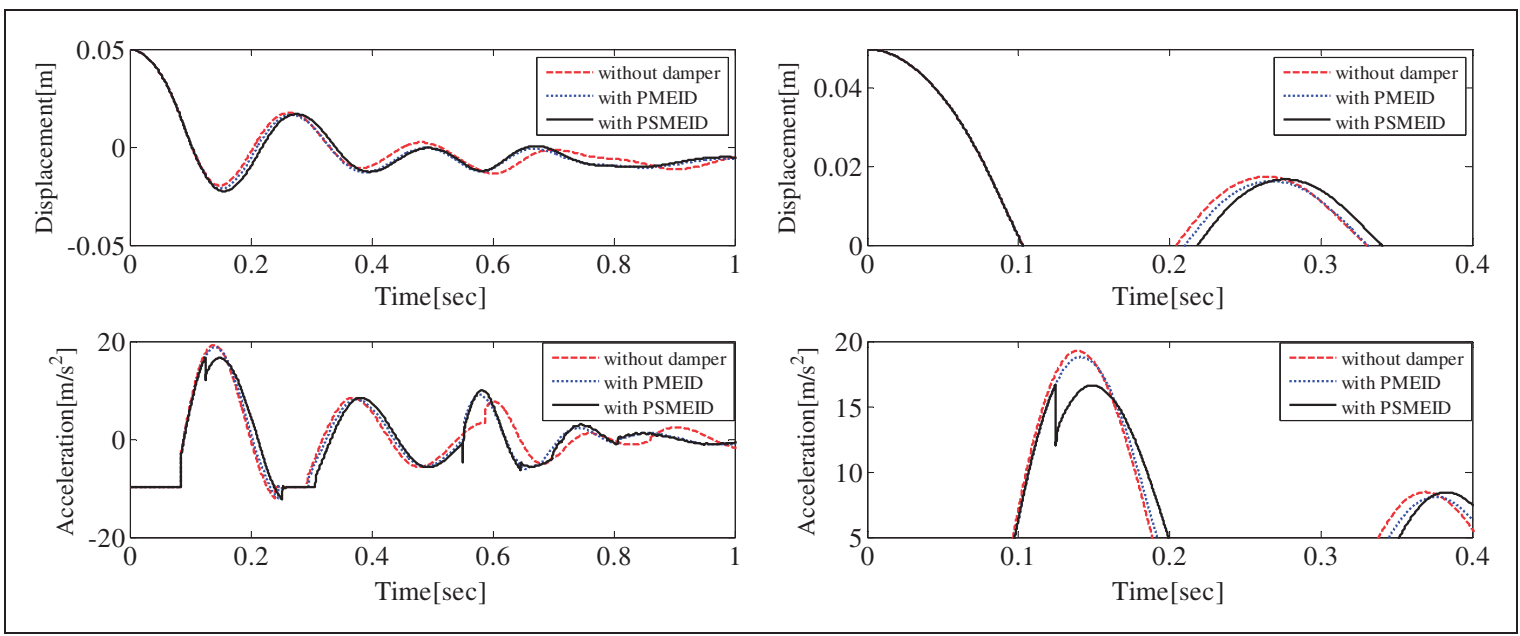

Figure I3. Displacement and acceleration of the UAV. 
the elevation of $0.05 \mathrm{~m}$ (as shown in Figure 13). The first impact between the main gear and the ground occurs at $t=0.083$ second. Between $t=0$ and $t=0.083$ second, the acceleration of the UAV is equal to the gravitational acceleration as shown in Figure 13. The negative value of the acceleration indicates that direction of the gravitational acceleration is downward. After the UAV had contact with the ground, the acceleration increased drastically and reached the maximum value at $t=0.14$ second. The maximum acceleration peak obtained using the PSMEID damper is smaller than that obtained from other mechanisms (shown in Figure 13). It can be seen from Figure 13 that the reduction of the acceleration peak using the PMEID and the PSMEID are $2.5 \%$ and $13.5 \%$, respectively.

Figure 14 shows the time histories of the rotational displacement (pitching angle) and the pitching acceleration of the UAV. Based on the results depicted in Figure 14, it can be observed that the nose landing gear began to touchdown on the runway at $t=0.6$ second without the damper. Using the PMEID and the PSMEID, the contact time of the nose landing gear started before $t=0.6$ second.

The result from Figure 14 shows that the pitching acceleration of the UAV was not greatly affected by the damper (PSMEID or PMEID). This may be due to $80 \%$ of the aircraft weight is supported by the main gear. As a consequence of the damper being located at the nose landing gear, the damper's performance decreases due to the additional rotational inertia load on the nose landing gear. Based on these results, in the next section, the PSMEID is only applied to the main landing gear system. Meanwhile, the nose landing gear is kept with passive damping using spring and dashpot element as shown in Figure 15.

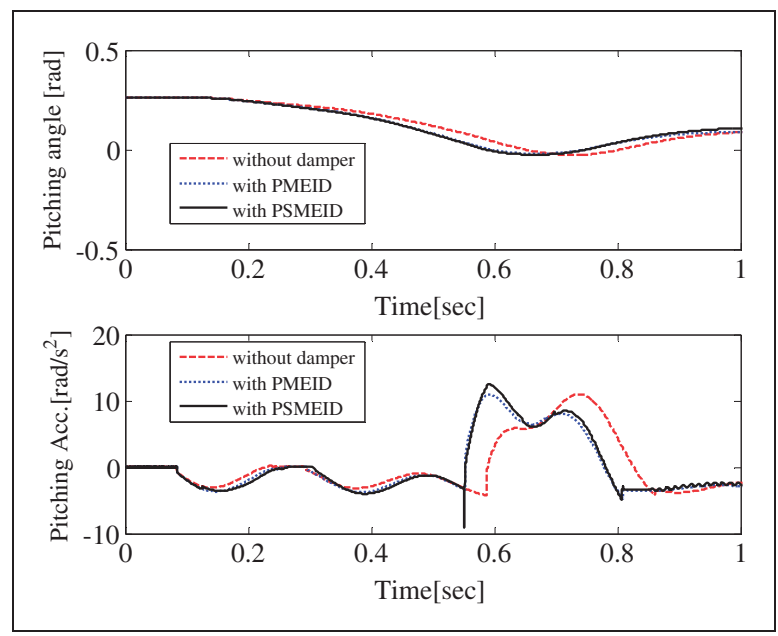

Figure 14. Pitching angle and pitching acceleration of UAV.
A comparison of the main mass maximum acceleration versus the initial deflection of the pre-straining spring at the main gear $\left(x_{p s l}\right)$ is given in Figure 16. As can be seen in Figure 16, increasing of the damper mass will reduce the maximum acceleration of the UAV. Furthermore, for low damper mass ratio $\left(m_{d l} / m=0.01\right)$, the larger attenuation of the UAV peak acceleration can be achieved by using a large deflection of the pre-straining spring. If the damper mass ratio increases, the optimum pre-straining spring deflection decreases as shown in Figure 16.

To investigate the mechanism of the PSMEID, the main mass acceleration time histories of two suboptimal conditions in Figure 16 are plotted in Figure 17. The sub-optimal points $\mathrm{A}$ and $\mathrm{B}$ are relating to the optimal conditions obtained using $m_{d l} / m=0.02$ and 0.06 , respectively. The related optimum gap for the sub-optimal conditions $\mathrm{A}$ and $\mathrm{B}$ are $3.0 \times 10^{-4}$ and $5.0 \times 10^{-4} \mathrm{~m}$, respectively. As shown in Figure 17, the acceleration responses are almost the same for both sub-optimal condition A and B. However, a slightly

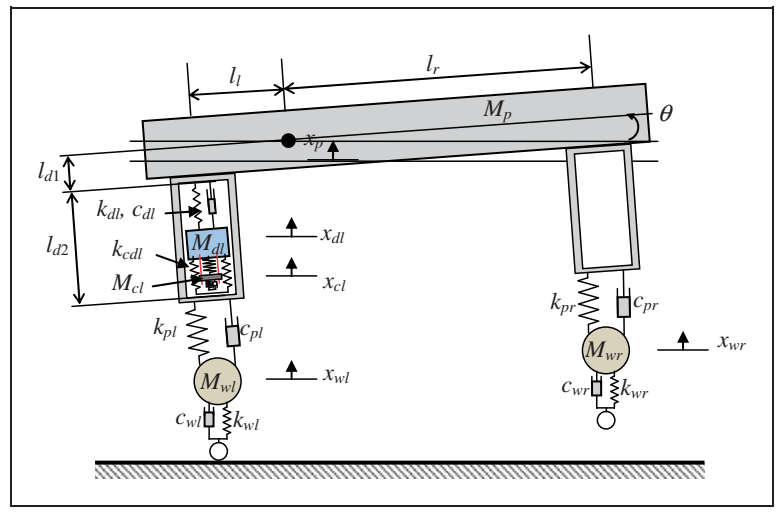

Figure I5. Dynamic model of a UAV with PSMEID as the main landing gear system.

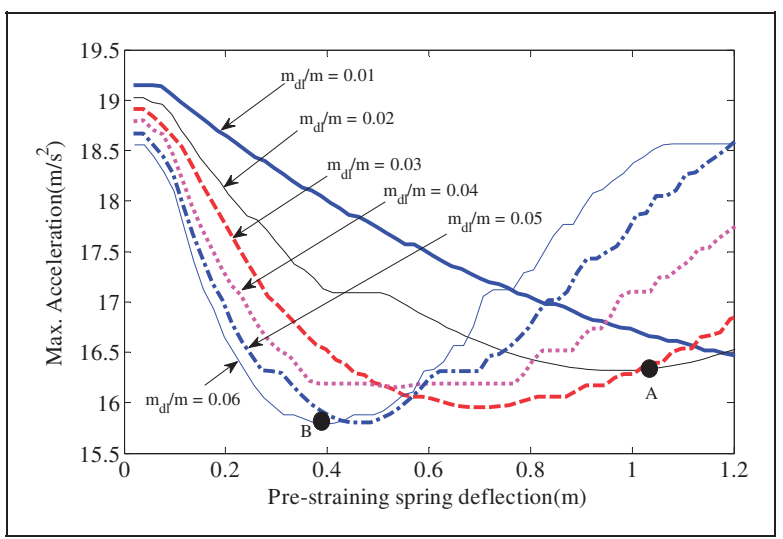

Figure 16. Maximum acceleration vs $x_{p s l}$. 


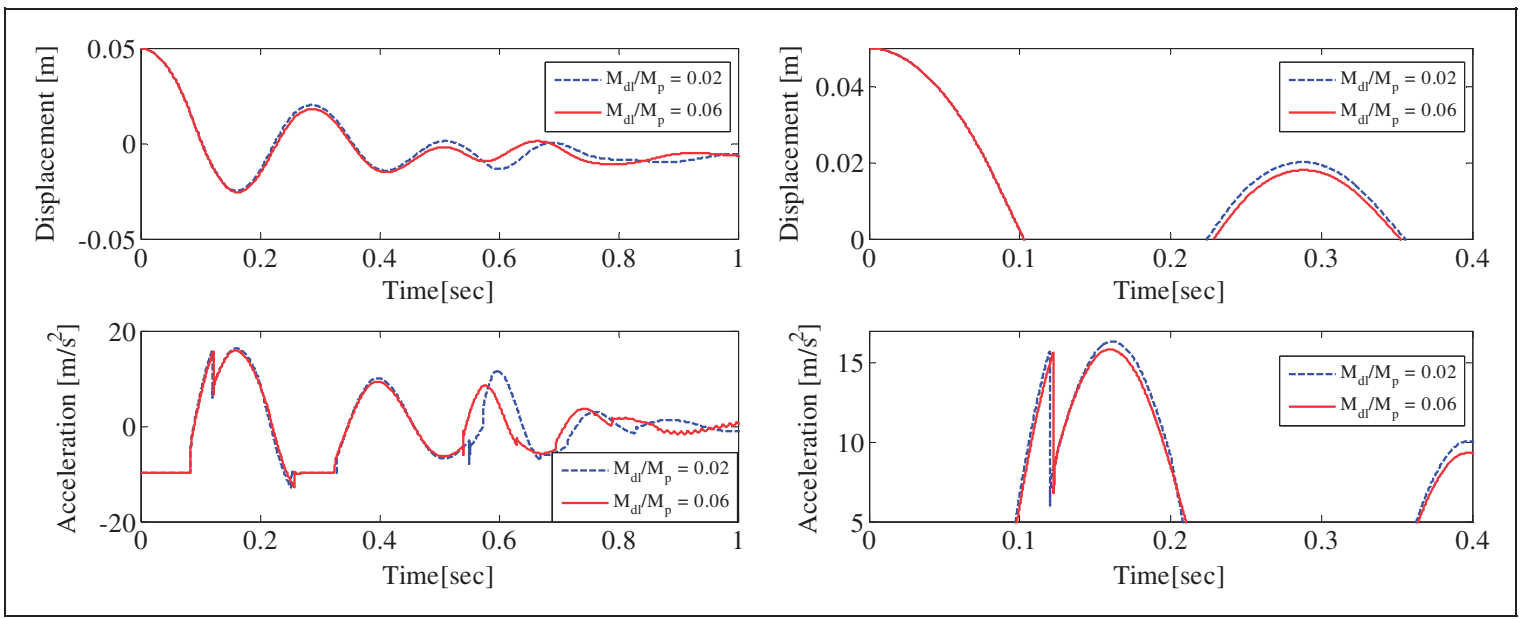

Figure 17. Displacement and acceleration for sub-optimal condition.

different result is obtained at $t=0.6$ second. At that time, the acceleration peak obtained using a larger mass ratio is much smaller than that obtained using the smaller mass ratio. The reason for this condition is that for the larger mass ratio, the location of the UAV's center of gravity is moving slightly to the main landing gear position. Therefore, the impact force generated when the nose gear touches the ground, which occurs at $t=0.6$ second is smaller in comparison to the case obtained with a smaller mass ratio.

\section{Conclusion}

This study introduces a new method to attenuate the shock response of the UAV landing process based on the momentum exchange principle (MEID). The damper performance is evaluated from the reduction of the UAV maximum shock acceleration and the force transmission during the landing impact. The PSMEID method, using a pre-straining spring mechanism, is used to increase the momentum exchange between the main mass and the damper mass. Application of the PSMEID for two cases of the UAV model were then analyzed. The main results obtained for the two cases of the UAV model with the PSMEID can be summarized as follows:

1. The simulation results using a simple lumped mass model show that the maximum acceleration and force transmission to the main mass can be reduced using a PSMEID damper. Furthermore, the energy balance analysis shows that the PSMEID damper can attenuate the shock-induced vibration of the main system by transferring part of its energy to the damper. The simulation results indicate that the energy transferred to the damper mass is almost twice that which it loses into heat energy on the damping components.

2. In the case of the two-dimensional model of the UAV, the maximum acceleration of the UAV's main mass can be reduced by increasing the mass ratio between the damper mass and the UAV's main mass. In the case of small mass ratio, the optimum condition for transferring the momentum can be obtained by using a large pre-straining spring deflection. These results indicate that the PSMEID can be considered as an alternative method for reducing the shock vibration response of the UAV landing gear system.

\section{Declaration of Conflicting Interests}

The author(s) declared no potential conflicts of interest with respect to the research, authorship, and/or publication of this article.

\section{Funding}

The author(s) disclosed receipt of the following financial support for the research, authorship, and/or publication of this article: The first author gratefully acknowledges the Andalas University International Publication Acceleration Grant No. 036/UN16/PL/AKS/2015 for funding this work.

\section{References}

Hara S and Ito R (2011) Momentum-Exchange-ImpactDamper-Based Shock Response Control for Planetary Exploration Spacecraft. Journal of Guidance,Control, and Dynamics 34: 1828-1838.

Hurmuzlu Y (1998) An Energy Based Coefficient of Restitution for Planar Impacts of Slender Bars with Masive External Surfaces. ASME Journal of Applied Mechanics 65: 952-962.

Iio T, Matsuhisa $\mathrm{H}$, Utsuno $\mathrm{H}$, Yamada $\mathrm{K}$ and Sawada $\mathrm{K}$ (2010) Reduction of Landing Impact of Spacecraft by 
Means of Momentum Exchange. In Proceedings of Dynamics and Design Conference 2010, Tokyo, No. 10-8, A16-No. 331.

Khebbache H (2012) Robust Control Algorithm Considering the Actuator Faults for Attitude Tracking of an UAV Quadrotor Aircraft. International Journal of Control and Automation 5: 55-66.

Kumar G (2012) Vision Based Autonomous Landing of an Unmanned Aerial Vehicle. Procedia Engineering 38: 2250-2256.

Nelson RC (1998) Flight Stability and Automatic Control, 2nd ed. Boston, Massachusetts: McGraw Hill.

Sadrey M (2009) Aircraft Configuration Optimization through Optimal Longitudinal Center of Gravity Range. In 9th AIAA Aviation Technology, Integration, and Operations Conference (ATIO), Hilton Head, South Carolina.

Sanoopkumar A (2003) Aircraft Landing Gear Simulation And Control, Master Theses. Department of Mechanical Engineering, Rochester Institute of Technology, Rochester, New York.

Skorupka Z, Kowalski W and Kajka R (2010) Electrically Driven And Controlled Landing Gear For Uav Up To $100 \mathrm{~kg}$ Of Take Off Mass. In Proceedings 24th
European Conference on Modelling and Simulation, Kuala Lumpur.

Son L, Bur M, Rusli M, Matuhisa H, Utsuno H and Yamada K (2015) Fundamental Study of Momentum Exchange Impact Damper Using Pre-Straining Spring Mechanism. International Journal of Acoustic and Vibration (in press).

Son L, Kawachi M, Matsuhisa H and Utsuno H (2007) Reducing Floor Impact Vibration and Sound Using a Momentum Exchange Impact Damper. Journal of System Design and Dynamics 1: 14-26.

Son L, Hara S, Yamada K and Matsuhisa H (2010) Experiment of Shock Vibration Control Using Active Momentum Exchange Impact Damper. Journal of Vibration and Control 16: 49-64.

Son L, Yamada K, Hara S, Utsuno $\mathrm{H}$ and Matsuhisa $\mathrm{H}$ (2008) Reduction of Floor Shock Vibration by Active Momentum Exchange Impact Damper. Journal of System Design and Dynamics 2: 930-939.

Zdravko T and Hinko W (2004) Dynamic Simulation of Transport Aircraft 3D LandingElastic Leg Shock Absorber Loads. In Proceedings European Congress on Computational Methods in Applied Sciences and Engineering ECCOMAS, Jyvaskyla. 